\title{
Análise Parasitológica de contaminantes de origem fecal em banheiros Femininos de uma Instituição de Ensino Superior do interior da Bahia
}

\author{
Marília de Oliveira Barboza ${ }^{1}$; Alana Soares Carvalho ${ }^{2}$
}

\begin{abstract}
Resumo: Os endoparasitas podem ser classificados em helmintos ou protozoários e representam um grave problema de saúde pública para a população mundial. As parasitoses são doenças que necessitam de fatores determinantes para que ocorra contaminação, tais como: condições sócio-econômicas e higiênico-sanitárias precárias, estado nutricional e imunológico alterado, idade, fatores ambientais e climáticos propícios. A prevalência elevada desses parasitas, que afetam principalmente indivíduos jovens, desencadeiam além de problemas gastrintestinais, baixo rendimento corporal e consequente atraso no desenvolvimento escolar. $\mathrm{O}$ presente estudo teve como objetivo avaliar a presença de ovos e larvas de helmintos e cistos de protozoários em elementos sanitários de banheiros de uma Instituição de Ensino Superior do Interior da Bahia. Foram coletadas no mês de junho de 2016 amostras de 95 elementos sanitários (tampa de vaso sanitário, assento sanitário, botão da descarga, maçaneta interna da porta, registro da torneira, botão do suporte para papel toalha e botão do suporte para sabonete) em 04 banheiros femininos. A técnica parasitológica utilizada para análise das lâminas foi o método de Graham (método da fita gomada), que revelou que do total de elementos sanitários analisados, 17 (61\%) mostraram-se contaminados por estruturas parasitárias. Nas amostras positivas foram encontrados Enterobius vermiculares, Taenia sp, Giardia lamblia, Entamoeba coli e larvas de nematódeos. Diante dos resultados encontrados torna-se relevante a adoção de práticas educativas de promoção à saúde a fim de reforçar a importância dos cuidados e hábitos diários que são necessários e adequados para evitar a contaminação e/ou reinfecção e possível disseminação de agentes parasitários, que possam ser nocivos à população acadêmica e demais usuários da instituição de ensino avaliada.
\end{abstract}

Palavras-Chave: Parasitas intestinais. Helmintos. Doenças parasitárias. Contaminação.

\section{Parasitological analysis of fecal contaminants in female restrooms of a Higher Education Institution in the interior of Bahia}

\begin{abstract}
Endoparasites can be classified as helminths or protozoa and represent a serious public health problem for the world population. Parasitic infections are diseases that require determining factors for contamination to occur, such as socio-economic and hygienic and sanitary conditions precarious, nutritional and immune status changed, age, environmental and climatic factors propitious. The high prevalence of these parasites, which affect mainly young individuals, trigger plus gastrointestinal problems, low body income and consequent delay in the school development. This study aimed to evaluate the presence of eggs and larvae of helminths and protozoan cysts in sanitary elements bathrooms of a higher education institution of Bahia Interior. Were collected in June 2016 samples of 95 sanitary elements (Toilet lid, toilet seat, the discharge button, inner door handle, tap record holder button to paper towel and support button to soap) in 04 women's restrooms. The parasitological technique used for analysis of the blades was the Graham method (gummed tape method), which revealed that the total sanitary elements analyzed, $17(61 \%)$ were shown to be contaminated by parasitic structures. In the positive samples were found Enterobius vermicularis, Taenia sp, Giardia lamblia, Entamoeba coli and larvae of nematodes. Given the results found is relevant to adopt educational promotion practices health in order to enhance the importance of daily care and habits that are necessary and appropriate to prevent contamination and / or reinfection and possible spread of parasitic agents that may be harmful to academic population and other users of assessed educational institution.
\end{abstract}

Keywords: Intestinal parasites. Helminths. Parasitic diseases. Contamination.

\footnotetext{
${ }^{1}$ Faculdade Independente do Nordeste - FAINOR. E-mail: mariliabarbozaa@ gmail.com.

${ }^{2}$ possui graduação em Farmácia pela Universidade Tiradentes e, Especialização em Análises Clínicas pela Universidade Castelo Branco. Atualmente é Preceptora da Faculdade Independente do Nordeste.
} 
Id on Line Revista Multidisciplinar e de Psicologia

Id on Line Multidisciplinary and Psycology Journal

\section{Introdução}

Os parasitas intestinais datam de milhares de anos e estão entre os patógenos que são mais frequentemente encontrados em seres humanos (FERREIRA et al., 2000). De acordo com Neves 2010, parasitismo é a relação entre seres vivos em que existe unilateralidade de benefícios, onde o hospedeiro é espoliado pelo parasita. Para a ocorrência de doenças dessa natureza é necessário haver fatores inerentes ao parasita, como número de exemplares, tamanho, localização, virulência e metabolismo. Em relação aos fatores inerentes ao hospedeiro, idade, estado nutricional, nível de resposta imune, intercorrência de outras doenças, hábitos e utilização de medicamentos são características que se mostram relevantes.

As infecções por helmintos e protozoários representam um grave problema de saúde pública no Brasil, devido ao grande número de pessoas que são infectadas por pelo menos um endoparasita, chegando a números que alcançam $90 \%$ da população (RAMOS, 2006). Essas infecções apresentam distribuição cosmopolita, sendo mais prevalente em regiões onde as condições de higiene são precárias e os fatores ambientais favoráveis (Pedroso \& Siqueira, 1997; Andrade et al., 2010).

Situações de baixas condições socioeconômicas, diferenças geográficas e climáticas, níveis variados de escolaridade, condições de baixo saneamento e o crescimento acelerado e não planejado de determinadas cidades, criam zonas periféricas empobrecidas e com moradias de infraestrutura inadequadas que favorecem a transmissão de parasitoses (NEVES, 2005).

As enteroparasitoses não se distribuem ocasionalmente ou de forma aleatória, é necessário que existam fatores de risco que determinem esta distribuição (NEVES, 2004). Os fatores motivadores para a ampliação das infecções por parasitas intestinais, além de correlacionados diretamente aos fatores socioeconômicos sanitários e ambientais, estão relacionados ainda à presença de indivíduos infectados, à contaminação fecal do meio, situações propícias ao desenvolvimento de estágios infectantes e, especialmente, do contato entre o indivíduo e a fonte de contaminação, que pode ocorrer de forma direta ou por meio de veículos como locais contaminados (REY, 2008). Portanto, a infecção por enteroparasitos ocorre por via oral, ingestão de água e alimentos contaminados ou contato direto com o solo que tenha a presença de larvas infectantes. Sendo comum também por meio de hábitos atípicos 
Id on Line Revista Multidisciplinar e de Psicologia

Id on Line Multidisciplinary and Psycology Journal

como a coprofagia e geofagia, fômites, pessoa a pessoa, mãos e utensílios mal higienizados (SILVA; BASTOS; BRENER, 2011).

Um indivíduo comprometido por endoparasitas pode sofrer danos, como obstrução intestinal, desnutrição, anemia por deficiência de ferro e quadros de diarreia e de má absorção, proporcionais à carga parasitária albergada pelo indivíduo (ESPINDOLA, 2014). A predominância de parasitoses intestinais em certas regiões do Brasil, bem como nos demais países em desenvolvimento, é sabidamente elevada. Parasitas como Ascaris lumbricoides, Trichuris trichiura e Entamoeba spp distribui-se por mais de 150 países e territórios, estabelecendo-se como uma das maiores endemias do país, devido à ampla distribuição geográfica e alta prevalência (SANTOS, et al., 2010).

Definir o nível de parasitismo ajuda na identificação dos problemas sanitários e sociais de uma população, já que os dados obtidos na pesquisa podem ser utilizados como um norteamento para aplicação de políticas sociais, econômicas e ambientais para o local estudado. Como a pesquisa em questão engloba somente o estudo de parasitas em elementos sanitários de uma instituição de ensino superior, é essencial que os funcionários e alunos da mesma sejam orientados acerca das noções básicas de higiene tanto quanto dos fatores de riscos existentes, para que desse modo as informações possam ser aplicadas a fim de evitar contaminações ou reinfecções.

Diante do exposto acima, o presente trabalho teve por objetivo identificar a presença de formas parasitárias em banheiros de uma instituição de ensino superior de Vitória da Conquista - Bahia - Brasil, verificando se estes ambientes constituem-se veículos de parasitos patogênicos.

\section{Material e Métodos}

A pesquisa foi desenvolvida a partir da coleta de amostras de 95 elementos presentes nos quatro banheiros femininos localizados no térreo, primeiro, segundo e terceiro andar do módulo de aulas da instituição de ensino em estudo. As amostras foram colhidas em objetos onde os estudantes e demais usuários tinham maior contato, sendo estes maçanetas internas, botões de 
Id on Line Revista Multidisciplinar e de Psicologia

Id on Line Multidisciplinary and Psycology Journal

descargas, assentos dos vasos sanitários, tampas dos vasos sanitários, torneiras, botões de suportes para sabonete e botões de suportes para papel toalha.

A coleta foi realizada em único dia no período da manhã e antes do expediente da limpeza.

Para as coletas, foi utilizada a técnica originalmente desenvolvida por Graham (1941) para o diagnóstico de Enterobius vermicularis, modificada para a superfície de objetos, que consistiu na aposição por cinco ou seis vezes de uma mesma fita adesiva transparente na superfície desejada. Em seguida a fita foi fixada em uma lâmina de vidro devidamente identificada com as iniciais do elemento pesquisado e a localização do banheiro analisado e posteriormente depositada em caixa de madeira própria para acondicionamento de lâminas de microscopia. As análises foram realizadas no laboratório de parasitologia da Faculdade Independente do Nordeste (FAINOR), utilizando-se microscópio óptico nos aumentos de 10X e 40X, não sendo utilizado nenhum tipo de corante.

\section{Resultados e Discussão}

As amostras foram coletadas em quatro banheiros femininos da instituição de ensino avaliada.

Coletou-se as amostras por objeto selecionado utilizando uma única fita para cada tipo de objeto de cada sanitário - As amostras foram agrupadas de acordo com o local da coleta e foi realizado um pool de cada objeto - sendo analisadas, no total, 28 lâminas. Destas, 17 (61\%) revelaram-se positivas e 11 (39\%) negativas.

Gráfico 1 - Frequência relativa (FR\%) do total de elementos sanitários positivos e negativos para algum tipo de estrutura parasitária presente em sanitários femininos de uma instituição de ensino superior do interior da Bahia. 


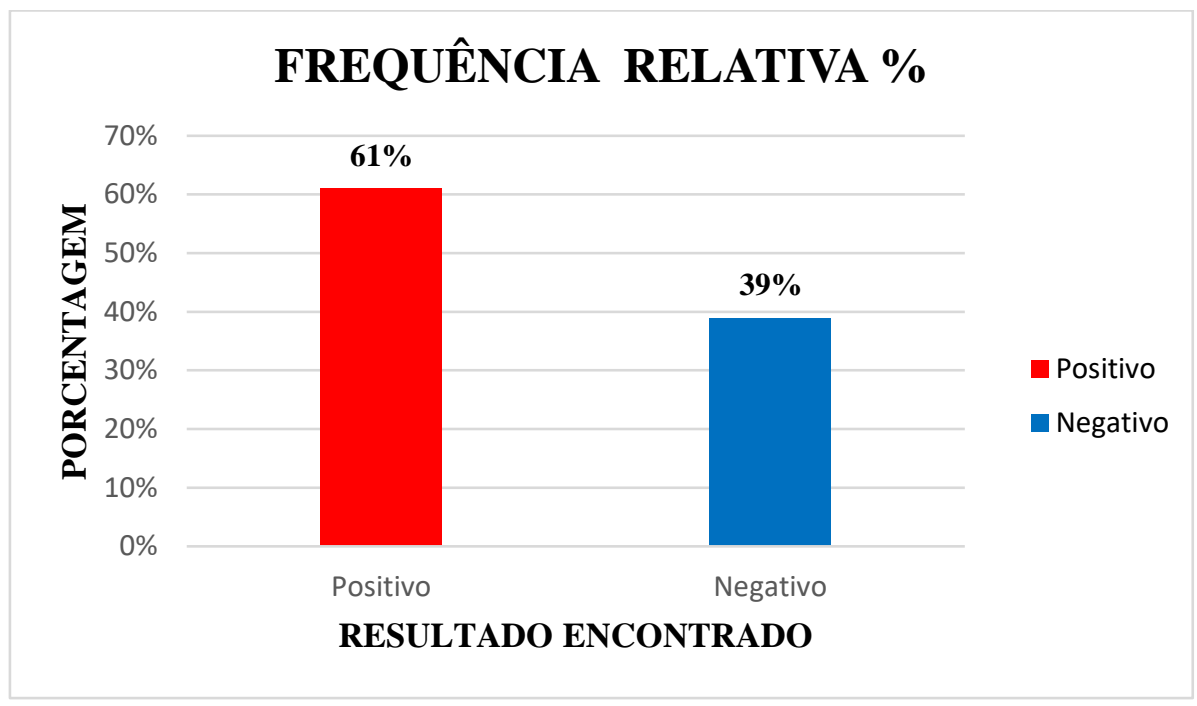

Fonte: Dados da pesquisa, 2016.

No estudo desenvolvido por Valadares et al. (2014), no qual foram analisados 80 elementos sanitários, cerca de $60 \%$ apresentaram-se contaminados por algum tipo de estrutura enteroparasitária, corroborando com esta pesquisa.

De acordo a tabela 1, foram amostrados 26, 26, 21 e 22 objetos por coleta, nos banheiros do térreo, $1^{\circ}, 2^{\circ}$ e $3^{\circ}$ andar, respectivamente. Em relação ao total de objetos analisados, foram examinados (avaliados) 18 assentos sanitários, 18 tampas de vasos sanitários, 18 botões de descargas, 18 maçanetas internas, 12 torneiras, 7 botões de suportes para papel toalha e 4 botões de suportes para sabonete totalizando 95 objetos. As quatro unidades pesquisadas mostraramse contaminadas.

Tabela 1 - Total de objetos analisados em sanitários femininos de uma instituição de ensino superior do interior da Bahia.

\begin{tabular}{lccccc}
\hline \multicolumn{1}{c}{$\begin{array}{c}\text { Objetos } \\
\text { analisados }\end{array}$} & $\begin{array}{c}\text { Banheiro } \\
\text { térreo }\end{array}$ & $\begin{array}{c}\text { Banheiro } \\
\mathbf{1}^{\mathbf{0}} \text { andar }\end{array}$ & $\begin{array}{c}\text { Banheiro } \\
\mathbf{2}^{\mathbf{0}} \text { andar }\end{array}$ & $\begin{array}{c}\text { Banheiro } \\
\mathbf{3}^{\mathbf{0}} \text { andar }\end{array}$ & $\begin{array}{c}\text { Objetos } \\
\text { examinados }\end{array}$ \\
\hline $\begin{array}{l}\text { Assento } \\
\text { sanitário }\end{array}$ & 5 & 5 & 4 & 4 & 18 \\
\hline Tampa do vaso & 5 & 5 & 4 & 4 & 18 \\
\hline $\begin{array}{l}\text { Botão de } \\
\text { descarga }\end{array}$ & 5 & 5 & 4 & 4 & 18 \\
\hline $\begin{array}{l}\text { Maçaneta } \\
\text { interna }\end{array}$ & 5 & 5 & 4 & 4 & 18 \\
\hline Torneira & 3 & 3 & 3 & 3 & 12 \\
\hline
\end{tabular}


Id on Line Revista Multidisciplinar e de Psicologia

Id on Line Multidisciplinary and Psycology Journal

\begin{tabular}{llllll}
\hline $\begin{array}{l}\text { Botão de suporte } \\
\text { para papel } \\
\text { toalha }\end{array}$ & 2 & 2 & 1 & 2 & 7 \\
\hline $\begin{array}{l}\text { Botão de suporte } \\
\text { para sabonete }\end{array}$ & 1 & 1 & 1 & 1 & 4 \\
\hline \begin{tabular}{l} 
Total \\
\hline
\end{tabular} & $\mathbf{2 6}$ & $\mathbf{2 6}$ & $\mathbf{2 1}$ & $\mathbf{2 2}$ & $\mathbf{9 5}$ \\
\hline
\end{tabular}

Fonte: Dados da pesquisa, 2016.

As formas evolutivas detectadas foram ovos de Enterobius vermicularis e Taenia $s p$, cistos de Giardia e Entamoeba coli e larva não identificada de nematódeo (Quadro 1). É possível observar que todos os tipos de elementos sanitários analisados apresentaram positividade para alguma forma parasitária. Destaca-se que três destes objetos (tampa do vaso sanitário, assento do vaso sanitário e botão de descarga) se mostraram contaminados por mais de uma espécie parasitária (Enterobius vermiculares sp, Taenia sp, Giardia, Entamoeba coli e Larva de nematoide não identificado).

Quadro 1 - Formas evolutivas presentes em objetos analisados em sanitários femininos de uma instituição de ensino superior do interior da Bahia.

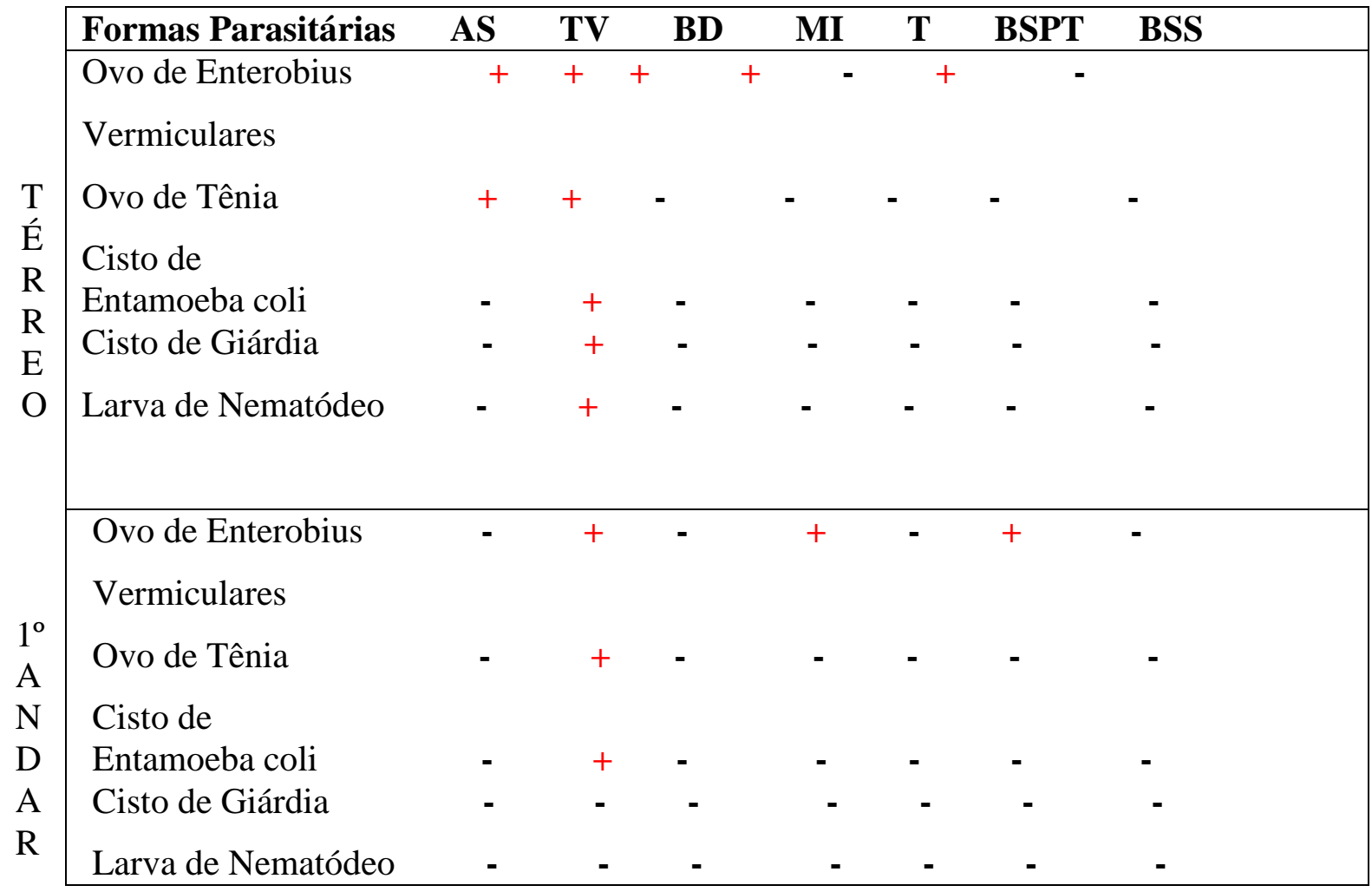




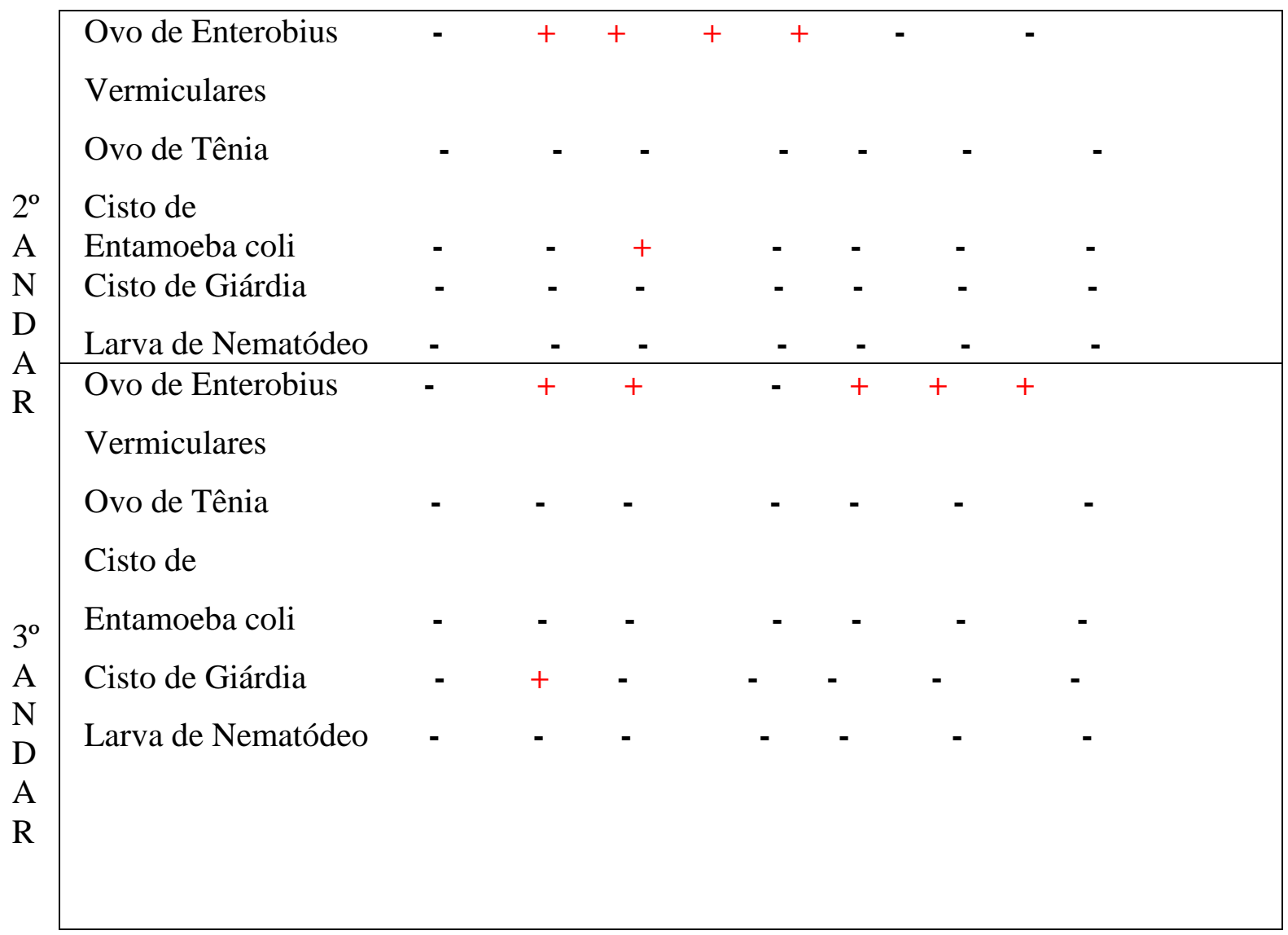

$\mathbf{A S}=$ Assento sanitário; $\mathbf{T V}=$ Tampa do vaso $; \mathbf{B D}=$ Botão de descarga; $\mathbf{M I}=$ Maçaneta interna; $\mathbf{T}=$ Torneira; BSPT $=$ Botão do suporte para papel toalha; $\mathbf{B S S}=$ Botão de suporte para sabonete.

Fonte: Dados da pesquisa, 2016.

Todos os elementos analisados revelaram-se contaminados por ovos de Enterobius vermicularis. Estes achados corroboram os trabalhos de Borges et al. (2009), que tal qual este foi encontrado ovos de Enterobius vermicularis em ônibus e banheiros públicos da cidade de Uberlândia-MG, reforçando a ameaça que estes locais podem representar para a saúde pública.

No gráfico 2 são apresentadas as frequências referentes às formas evolutivas encontradas nas lâminas colhidas nos sanitários da Instituição pesquisada. Dentre os elementos sanitários analisados, a tampa do vaso sanitário apresentou o maior índice de contaminação (100\%). A função deste objeto pode explicar o alto índice de contaminação deste em detrimento aos demais elementos sanitários. O segundo maior índice de contaminação ocorreu nos botões de descargas, maçanetas internas e botões do suporte para papel toalha (75\%), seguido das torneiras que obtiveram o terceiro maior índice (50\%). Os elementos sanitários com o menor índice de contaminação foram os assentos de vasos e botões de suporte para sabonete (25\%). 
Id on Line Revista Multidisciplinar e de Psicologia

Id on Line Multidisciplinary and Psycology Journal

Gráfico 2 - Percentual de contaminação pertinente às formas parasitárias encontradas nas lâminas colhidas em objetos analisados em sanitários femininos de uma instituição de ensino superior do interior da Bahia.

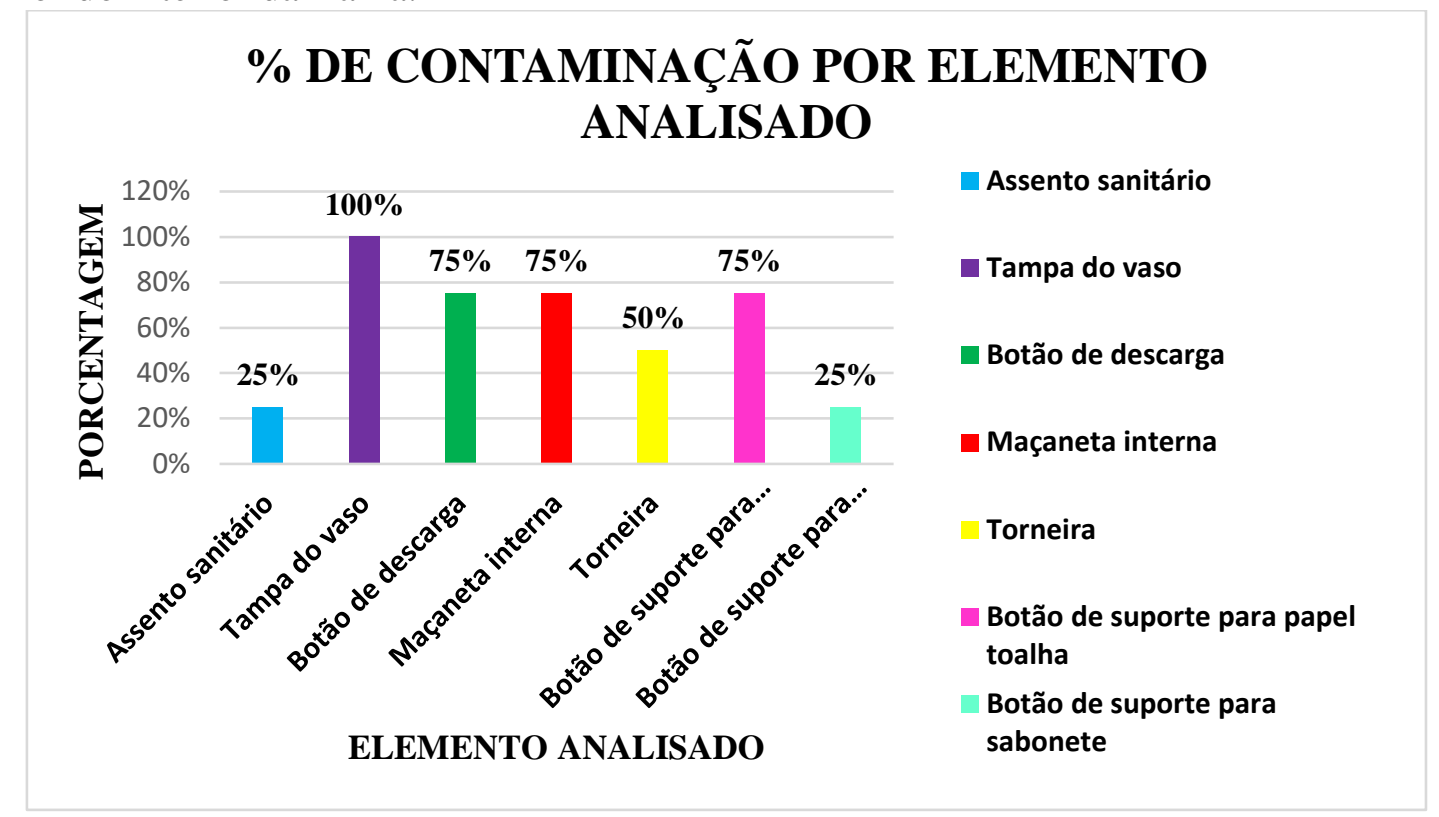

Fonte: Dados da pesquisa, 2016.

Nos estudos de Sobrinho et al. (1995), Silva, Bastos e Brener (2011), o assento sanitário foi o elemento que apresentou o maior percentual de contaminação, contrário ao resultado detectado nesta análise.

Embora os banheiros analisados apresentem instalações em boas condições de funcionamento, ficou evidenciada a importância da proposta inicial deste estudo, visto que todas as unidades analisadas se mostraram contaminadas por parasitas.

A presença de ovos de Enterobius vermiculares serve como um alerta aos usuários do ambiente analisado, devido à facilidade na transmissão desse parasito que possui ovos muito leves que são facilmente carreados e tornam-se infectantes dentro de poucas horas quando entram em contato com oxigênio. A infecção por esse parasito geralmente é assintomática, porém em casos sintomáticos pode ocasionar em humanos prurido anal, enterite catarral, apêndicite, insônia, nervosismo, vaginite, metrite, salpingite e ovarite, além de granulomas hepático, renal e prostático (REY, 2008).

Ovos de tênia foram encontrados em vários pools e assim como os ovos de Enterobius vermiculares esses ovos são leves e podem ser facilmente transportados pelo vento a longas distâncias provocando a infecção pela ingestão de ovos contaminados (PIRES, 2008). O ovo de 
Id on Line Revista Multidisciplinar e de Psicologia

Id on Line Multidisciplinary and Psycology Journal

Taenia solium quando ingerido pode ocasionar a cisticercose humana, que provoca quadros de convulsões e hipertensão intracraniana entre outros. (SILVA-VERGARA et al., 1998). Não é possível dizer se os ovos encontrados eram de Taenia solium ou Taenia saginata, pois os mesmos são "indistinguíveis microscopicamente" (NEVES, 2002).

Destaca-se que Giardia lamblia, encontrado em algumas estruturas, é um dos parasitos intestinais que apresenta maior predominância em humanos e caracteriza o principal fator de diarreia não viral (TASHIMA, 2007). A giardíase geralmente tem como consequência enterites com aparecimento de diarreias associadas a dores abdominais crônicas, caracterizada por um quadro de esteatorreia, flatulência, aumento abdominal e cansaço. Está associada ainda à má absorção de vitaminas lipossolúveis (A, D, E, K) o que leva a complicações como perda de peso e anemia (REY, 2008; VIEIRA, 2009).

Cistos de Entamoeba coli, também estavam presentes nos sanitários. Apesar de não patogênicos, esses protozoários possuem um papel importante como indicadores de contaminação fecal de origem humana, uma vez que são enteroparasitos (CORDEIRO; MACEDO, 2007).

$\mathrm{Na}$ tampa do vaso sanitário do banheiro do andar térreo foi verificada a presença de uma larva íntegra de nematódeo, porém a técnica utilizada não permitiu identificar a espécie do parasito. De acordo CORDEIRO; MACEDO, 2007, esses parasitos da classe nematoda de importância médica podem ser Strongyloides stercoralis e Ancilostomídeos, logo se sugere que a larva encontrada pode pertencer a um desses gêneros.

A má higienização das mãos dos usuários dos sanitários da Instituição, aliada à precariedade na limpeza efetuada no ambiente, possivelmente justifique a elevada taxa de contaminação dos elementos sanitários por estruturas parasitárias verificada no presente estudo.

Frente aos resultados desse estudo, bem como de outras pesquisas semelhantes (BORGES et al., 2009; VALADARES et al., 2014), que estão em consonância, como o primeiro estudo desse gênero realizado em 1974 em um orfanato por Silva, Bastos e Brener, 2011, foi possível observar que elementos sanitários são caracterizados como importantes meios de disseminação e contaminação de estruturas parasitárias. A existência de estruturas diversificadas como cistos de protozoários, ovos e larvas de helmintos nos elementos sanitários analisados confirma o importante papel desses objetos como possíveis transmissores de parasitos intestinais (VALADARES et al., 2014). 
Id on Line Revista Multidisciplinar e de Psicologia

Id on Line Multidisciplinary and Psycology Journal

\section{Conclusão}

Diante dos resultados do presente estudo que mostrou um elevado percentual de contaminação parasitária nos elementos sanitários dos banheiros analisados foi possível confirmar e reforçar que estes ambientes constituem uma fonte potencial para a veiculação e transmissão de parasitos intestinais de importância médica para humanos. Entretanto não se pode concluir que o índice de contaminação dos usuários dos banheiros da Instituição pesquisada seja proporcional ao resultado do estudo, devido ao desconhecimento dessas frequências.

Há necessidade que sejam adotadas ações educativas de promoção da saúde para a população que utiliza os banheiros da unidade de ensino avaliada a fim de reforçar a importância dos cuidados e hábitos diários que são necessários e adequados para evitar a contaminação e/ou reinfecção e possível disseminação de agentes parasitários, que possam ser nocivos à saúde humana.

Nota-se, portanto, a necessidade de uma avaliação tanto na forma de higienização dos elementos sanitários dos banheiros, bem como da eficiência dos produtos de limpeza utilizados a fim de minimizar o risco de estes ambientes constituírem-se facilitadores da disseminação de parasitoses.

\section{Referências}

ANDRADE EC, LEITE ICG, RODRIGUES VO, CESCA MG. Parasitoses intestinais: Uma revisão sobre seus aspectos sociais, epidemiológicos, clínicos e terapêuticos. Rev APS Juiz de Fora 13: 231-240, 2010.

BORGES, C.A.; COSTA-CRUZ, J.M. \& PAULA, F.M. - Intestinal parasites inside public restrooms and buses from the city of Uberlândia, Minas Gerais, Brazil. Rev. Inst. Med. trop. S. Paulo, 51(4): 223-225, 2009.

CORDEIRO, T. G. P.; MACEDO, H. W. Amebíase. Revista de Patologia Tropical, v. 36, n. 2, p. 119-128, 2007.

ESPINDOLA CMO, 2014. Avaliação epidemiológica das parasitoses intestinais no Parque Oswaldo Cruz, Manguinhos, Rio de Janeiro, RJ. Dissertação (Mestrado em Medicina 
Id on Line Revista Multidisciplinar e de Psicologia

Id on Line Multidisciplinary and Psycology Journal

Tropical, Instituto Oswaldo Cruz.). Orientador: Prof. Dr. Antonio Henrique Almeida de Moraes Neto; Prof. Dr. Maurício Carvalho de Vasconcellos.

FERREIRA UM, FERREIRA CS, MONTEIRO CA. Tendência secular das parasitoses intestinais na cidade de São Paulo (1984-1996). Rev Saúde Pública. 2000; 34:73-82.

NEVES, D. P. Parasitologia Humana. 11. Ed. Atheneu. 2002. P.457-459.

Parasitologia humana. 11. ed. São Paulo: Atheneu, 2004.

. Parasitologia humana. 11. ed. São Paulo: Atheneu, 2005.

Parasitologia humana. 11. ed. São Paulo: Atheneu, 2010.

PEDROSO RS, SIQUEIRA RV. Pesquisa de cistos de protozoários, larvas e ovos de helmintos em chupetas. J Ped 73: 21-25, 1997.

PIRES, W. M. Complexo Teniase x Cisticercose. 25f. 2008. Tese (Especialização Lato Sensu em Higiene e Inspeção de Produtos de Origem Animal) - Instituto Qualittas de PosGraduação, Palmas, 2008.

RAMOS, G.C.S.C. Correlação entre parasitoses intestinais, estado nutricional, condições socioeconômicas e sanitárias de crianças de três creches públicas do município de Niterói. Dissertação (Mestrado em Patologia Clínica e Análises Clínicas, Universidade Federal Fluminense). Orientador: Heloisa Werneck de Macedo, 2006.

REY, L. Parasitologia: parasitos e doenças parasitárias do homem nos trópicos ocidentais. 4ed. Rio de Janeiro: Guanabara, 2008.

SANTOS, F. S. dos et al. Prevalência de enteroparasitismo em crianças de comunidades ribeirinhas do município de Coari, médio Solimões, Amazonas, Brasil. Revista Pan Amazônica de Saúde, Ananindeua - Pará v.1, n.4, p.23-28, 2010.

SILVA, A. C. O.; BASTOS, O. M. P.; BRENER, B. Estudo da contaminação de elementos sanitários por estruturas enteroparasitárias em cinco pré-escolas públicas da cidade de Patrocínio - MG. Revista de Patologia Tropical, v. 40, n. 4, p. 315-322, 2011.

SILVA-VERGARA; M. L.; PRATA, A.; VELlOSO, H.; NETTO, S.; VIEIRA, C. O.; CASTRO,J. H.; MICHELETTI, L. G.; OTAÑO, A. S.; JÚNIOR. J. F. Risk factors associated with taeniasis-cysticercosis in Lagamar, Minas Gerais State, Brazil. Revista da Sociedade Brasileira de Medicina Tropical. V.31, n.1, p.65-71, 1998.

SOBRINHO, T. A.; COELHO, L. M. P. S.; OLIVEIRA, M.; MARTINS, J. T. JÚNIOR, R. A. J.; OLIVEIRA, R. P.; PAULA, M. A.; JÚNIOR, M. W. P.; MIYAZAKI, S. M. Estudo da frequência de ovos de helmintos intestinais em sanitários de uso público de Sorocaba, SP. Revista da Sociedade Brasileira de Medicina Tropical, v. 28, n. 1, p. 33-37, 1995. 
TASHIMA, N. T. Estudo clássico e molecular de Giardia lamblia isolada de uma população infantil da região de Presidente Prudente SP/ Brasil. 2007. 80f. Tese (Doutorado em análises clínicas) - Faculdade de Ciências Farmacêuticas, Universidade Estadual Paulista "Julio de Mesquita Filho", Araraquara, 2007. Disponível em: <http://www.athena.biblioteca.unesp.br/exlibris/bd/bfa/33004030081P7/2007/tashima _nt_dr_arafcf.pdf>. Acesso em: 03 set. 2016.

VALADARES, M.B.; FONSECA, H.M. \& WELTER, A. Parasitos intestinais em sanitários públicos da cidade de Palmas - TO. UnirG, Gurupi, TO, Brasil. Rev. CEREUS, v. 6, n. 1, jan./abr. 2014.

VIEIRA, M. A. G. Enteroparasitoses e anemia ferropriva em gestantes assistidas na unidade saúde da família de Nova Viçosa e Posses, no município de Viçosa-MG. 2009. Dissertação (Pós-graduação em medicina veterinária) - Universidade Federal de Viçosa, 2009. Disponível em: <http://www.dominiopublico.gov.br/pesquisa/DetalheObraForm.do?select_action\&co _obra=154919>. Acesso em: 03 de set. 2016.

Como citar este artigo (Formato ABNT):

BARBOZA, M.O.; CARVALHO, A.S. Educação Análise Parasitológica de contaminantes de origem fecal em banheiros Femininos de uma Instituição de Ensino Superior do interior da Bahia. Id on Line Revista Multidisciplinar e de Psicologia, Janeiro de 2017, vol.10, n.33, p. 237-248. ISSN: 1981-1179.

Recebido: $02 / 12 / 2016$

Aceito: $02 / 12 / 2016$ 